NBER WORKING PAPER SERIES

\title{
DO FIELD EXPERIMENTS ON LABOR AND HOUSING MARKETS OVERSTATE DISCRIMINATION? A RE-EXAMINATION OF THE EVIDENCE
}

\author{
David Neumark \\ Judith Rich \\ Working Paper 22278 \\ http://www.nber.org/papers/w22278 \\ NATIONAL BUREAU OF ECONOMIC RESEARCH \\ 1050 Massachusetts Avenue \\ Cambridge, MA 02138 \\ May 2016, Revised August 2017
}

We wish to thank the following authors of studies who generously provided their raw data: Ali Ahmed, Lina Andersson, and Mats Hammarstedt; Stijn Baert, Bart Cockx, Niels Gheyle, and Cora Vandamme; Marianne Bertrand and Sendhil Mullainathan; Mariano Bosch, M. Angeles Carnero, and Lídia Farré; Magnus Carlsson and Stefan Eriksson; Dan-Olof Rooth (also with Magnus Carlsson); Nick Drydakis; Michael Ewens, Bryan Tomlin, and Liang Choon Wang; Hwok-Aun Lee and Muhammad Abdul Khalid; and Phil Oreopoulos. We thank Nick Drydakis and Philip Oreopoulos, and three anonymous referees, for helpful comments. The views expressed herein are those of the authors and do not necessarily reflect the views of the National Bureau of Economic Research.

NBER working papers are circulated for discussion and comment purposes. They have not been peer-reviewed or been subject to the review by the NBER Board of Directors that accompanies official NBER publications.

(C) 2016 by David Neumark and Judith Rich. All rights reserved. Short sections of text, not to exceed two paragraphs, may be quoted without explicit permission provided that full credit, including $\odot$ notice, is given to the source. 
Do Field Experiments on Labor and Housing Markets Overstate Discrimination? A Re-examination of the Evidence

David Neumark and Judith Rich

NBER Working Paper No. 22278

May 2016, Revised August 2017

JEL No. J71

\begin{abstract}
There have been over 80 field experiments on traditional dimensions of discrimination in labor and housing markets since 2000, in 23 countries. These studies nearly always find evidence of discrimination against minorities. However, the estimates of discrimination in these studies can be biased if there is differential variation in the unobservable determinants of productivity or quality of majority and minority groups, so it is possible that this experimental literature as a whole overstates the evidence of discrimination. We re-assess the evidence from the 10 existing studies of discrimination that have sufficient information to correct for this bias. For the housing market studies, the estimated effect of discrimination is robust to this correction. For the labor market studies, in contrast, the evidence is less robust, as just over half of the estimates of discrimination either fall to near zero, become statistically insignificant, or change sign.
\end{abstract}

\author{
David Neumark \\ Department of Economics \\ University of California at Irvine \\ 3151 Social Science Plaza \\ Irvine, CA 92697 \\ and NBER \\ dneumark@uci.edu \\ Judith Rich \\ Economics and Finance Department \\ University of Portsmouth \\ Richmond Building Portland Street \\ Portsmouth PO1 3DE \\ United Kingdom \\ judy.rich@port.ac.uk
}




\section{Introduction}

Field experiments - specifically, audit or correspondence studies - have been used extensively to test for discrimination in markets. In audit studies of labor market discrimination, fake job candidates (“testers”) of different races, ethnicities, etc., who are sometimes actors, are sent to interview for jobs (or in some early studies, apply by telephone). The candidates have similar resumes and are often trained to act, speak, and dress similarly. Correspondence studies, in contrast, use fictitious job applicants who exist on paper only (or now, electronically), and differ systematically only on group membership. The response captured in correspondence studies is a “call-back” for an interview or a closely related positive response. In contrast, the final outcome in audit studies is actual job offers. Differences in outcomes between groups are likely attributable to discrimination, although there are, naturally, some subtle issues of interpretation - including the fact that such differences can be attributable to either taste discrimination or statistical discrimination. Audit and correspondence (AC) studies have also been used to study discrimination in housing markets. In audit studies, the testers of different races, ethnicities, etc., are sent to inquire about properties for rent or sale. In correspondence studies the fictitious inquiry is submitted electronically, applying online to advertised properties for rent or sale.

AC studies are widely regarded as providing more rigorous evidence on discrimination than can be obtained from non-experimental evidence in which group membership may be correlated with unobservables. ${ }^{1}$ Nonetheless, AC studies have come in for criticism (Heckman and Siegelman, 1993; Heckman, 1998). The most challenging criticism of these studies is that, in the standard implementation, the resulting estimate of discrimination can be biased in either

\footnotetext{
${ }^{1}$ The methods and empirical findings from these studies have been reviewed by Pager (2007), Riach and Rich (2002), Rich (2014), and Neumark (2016). There are, additionally, similar studies of discrimination in consumer markets (e.g., Doleac and Stein, 2013).
} 
direction - or equivalently, discrimination can be unidentified. This problem arises when the variances of the unobservables differ across the groups studied, something that cannot be ruled out or easily controlled in AC studies, and indeed a difference in the variances of unobservables is at the core of early models of statistical discrimination (Aigner and Cain, 1977). This criticism which we refer to as the "Heckman-Siegelman critique" - holds even under quite ideal conditions (detailed later) in which other potential research design flaws that Heckman and Siegelman discuss are absent.

A statistical method that can lead to unbiased estimates of discrimination using data from AC studies, relying on identifying assumption, was proposed in Neumark (2012). As explained below, most past AC studies do not have the requisite data, which are applicant or other characteristics aside from the group identifier that shift the probability of call-backs or hires. However, we have identified 10 studies of discrimination against minorities (based on race, ethnicity, or sexual orientation) in labor and housing markets conducted over the last couple of decades that do include the requisite data. ${ }^{2}$

These 10 studies - just like nearly all of the far greater number of AC studies that do not have the requisite data - find evidence of discrimination against ethnic or racial minorities, immigrants, or gays and lesbians. ${ }^{3}$ We have obtained the original data from the authors of these studies, and our goal in this paper is to test whether this evidence is robust to confronting the data with the Heckman-Siegelman critique. Specifically, implementing the correction for bias from differences in the variances of unobservables across groups, do these studies still uniformly point

\footnotetext{
2 The studies are: Ahmed et al. (2010); Baert et al. (2015); Bertrand and Mullainathan (2004) - the data used in Neumark (2012); Bosch et al. (2010); Carlsson and Eriksson (2014); Carlsson and Rooth (2007); Drydakis (2014); Ewens et al. (2014); Lee and Khalid (2016); and Oreopoulos (2011).

${ }^{3}$ For the most recent review of a large number of AC studies, see Neumark (2016).
} 
to discrimination? Some very recent AC studies have implemented this bias correction. ${ }^{4}$ Our goal in this paper is to revisit past studies that do not address the Heckman-Siegelman critique, to assess whether the near-uniform findings of discrimination from the large body of past research is robust to addressing this critique. We cannot re-examine all such studies. But we do, we believe, re-examine the complete set of such studies that focus on traditional dimensions of discrimination and have (accessible) the data required to address this critique.

After providing some background details on these studies, we explain the approach and report results. To summarize the results briefly, for the housing market studies the estimated effects of discrimination are robust to this correction. For the labor market studies, in contrast, the evidence is less robust; in about half of the cases covered in these studies, the estimated effect of discrimination either falls to near zero or becomes statistically insignificant, and in one the sign changes. The results for the labor market, in particular, suggest that researchers need to build into future AC studies the data and experimental design needed to address the Heckman-Siegelman critique, and that further work on different ways to eliminate bias from AC studies estimates of discrimination is warranted. More substantively, our re-examination of the evidence suggests that the overall body of experimental evidence on labor market discrimination provides a less clear signal of discrimination than one would draw from the results reported in the existing studies.

\section{The field experiments covered in this paper}

The field experiments re-analyzed in this paper are one of three broad types: studies of ethnic/immigrant or race discrimination in labor markets; studies of sexual orientation discrimination in labor markets; and studies of ethnic/immigrant or race discrimination in rental

\footnotetext{
${ }^{4}$ See Baert (2014, 2015, 2016), Carlsson et al. (2013), Neumark et al. (2015), and Nunley et al. (2015). Baert and Verhofstadt (2015) also do this, although in relation to criminal background (juvenile delinquency), which is outside the scope of discrimination studies covered in the present paper.
} 
housing markets. Many of the details and results of these studies are discussed in Rich (2014) and Neumark (2016). Here we focus only on what is essential to understand the analysis of bias from differences in unobservables that we implement in this paper. Readers interested in more details on these specific studies, and the techniques used more generally, should see our surveys (or of course the original papers). We do not go into more detail because our goal in this paper is not to compare or critique other dimensions of these studies, but rather just to consider the robustness of the conclusions to addressing the Heckman-Siegelman critique. ${ }^{5}$

What distinguishes these 10 studies from the others in the literature is that they use applicants distinguished not only by race, ethnicity (including immigrant origin), or sexual orientation, but also by different levels of qualifications. In these studies, this was done to ask, in a general way, whether the evidence of discrimination by ethnicity, race, or sexual orientation differed for applicants with different levels of qualifications. ${ }^{6}$ As discussed in the next section, however, the availability of data with variation in applicant qualifications is exactly what is needed to implement the empirical method that addresses the Heckman-Siegelman critique.

Baert et al. (2015), Bertrand and Mullainathan (2004), Carlsson and Rooth (2007), Drydakis (2014), and Lee and Khalid (2016) all used matched pairs (sets) of applicants, with two (or more)

\footnotetext{
${ }^{5}$ There are also field experiments investigating differences in hiring outcomes based on other characteristics, such as criminal background, mental or physical illness, facial attractiveness, veteran status, or socio-economic background or class. While these kinds of differences are not the focus of our paper (even though some could be interpreted as discrimination), the experimental designs in these papers do not generate the data needed to implement this empirical method, with the exception of Baert and Balcaen (2013), who implement this method in relation to differential treatment based on military service, and find no evidence of bias from differences in the variances of unobservables.

${ }^{6}$ The first study of this type (Jowell and Prescott-Clarke, 1970) considered this issue. The study compared job offer outcomes for immigrant versus white British applicants, and gave half the applications in each group higher qualifications with regard to education. (There was also variation among the immigrants only in whether they were English-speaking and whether secondary education was in Britain, although this kind of variation that does not apply equally to majority and minority groups is not as useful.) The more recent studies with such data that we re-examine in the present paper are those for which we could recover the data from authors.
} 
applications sent to each job vacancy. Oreopoulos (2011) considered differences for many different ethnic groups (relative to native Canadians), in some cases also signaling immigrant status, and sent multiple resumes for each job vacancy. Across these studies, on the resumes used, which were either real resumes the authors found or resumes generated randomly from elements of other resumes, race or ethnicity was signalled by name, and immigrant status in addition to ethnicity was sometimes further signalled by education or work experience in a foreign country (Oreopoulos, 2011). Sexual orientation was signalled by participation in an organization active on behalf of the gay community or a gay organization.

There have been fewer studies of discrimination in housing markets in the broader literature. In the housing market experiments we re-examine, only Bosch et al. (2010) used matched pairs, while the other three (Ahmed et al., 2010; Ewens et al., 2014; Carlsson and Eriksson, 2014) sent a single rental enquiry. An accompanying message providing details on the applicant was attached, in which the researchers manipulated the information provided - ethnicity and race, as well as other qualifications or the applicant's job, which indicated ability to pay. In these studies, signaling is done by name, although Bosch et al. (2010) interpret their results for Moroccan versus Spanish names as measuring discrimination against immigrants.

Other qualifications also varied across the resumes or applications - and this variation in qualifications is essential for implementing the correction for bias from differences in variances of unobservables. The variables used in each study are described in Tables 2A, 2B, and 3, which report our results from re-analyzing the data from these studies (discussed in detail below). For example, Bertrand and Mullainathan (2004) generally sent four applications to each job. They created two matched pairs of applicants, one with low-quality background and another pair with high-quality background. The quality of the applicant varied based on labor market experience, career profiles, employment history, and skills such as employment experience gained either over 
summer or while at school, volunteering, extra computer skills, certification degrees, foreign language skills, honors, or some military experience. Carlsson and Rooth (2007) signalled similar additional information on applicants as Bertrand and Mullainathan, as well as different spells of unemployment, work experience over the summer, overqualified or not, personality traits, and cultural and sporting activities listed as hobbies and interests. Oreopoulos (2011) varied the information provided on the extent of foreign education and foreign experience as well as language skills and certification and masters degrees. Drydakis (2014) used an accompanying cover letter to provide more favorable information about applicants in some cases, including mentioning grades, previous job responsibilities and tasks, and personality characteristics associated with work commitment; these same applicants also included letters of references that more strongly signalled positive work traits such as teamwork and loyalty to the firm. Lee and Khalid (2016) varied factors such as private versus public university, grades, and English proficiency.

In the housing market tests, researchers manipulated the information on the applicant, using an accompanying message, to explore the impact of basic, negative, or positive information - such as habits (smoking, exercise, and nightclub attendance, in Carlsson and Eriksson, 2007), variation in smoking and credit rating (in Ewens et al., 2014), and information on positive characteristics like work history, education, lack of payment complaints, etc. (Ahmed et al., 2010) or stable occupations and contracts (Bosch et al., 2010).

The richness and number of qualifications that researchers chose to vary across the applicants differ quite a bit across these studies. For the labor market studies, these qualifications generally pertain to education, experience, and skills, but sometimes extend to attempts to convey something about the applicant's personality or hobbies, the order of the application, and other things. One of the housing studies (Carlsson and Eriksson, 2014) tries to provide information on the applicant's 
lifestyle, which could be relevant to a potential landlord. We do not discuss the different qualifications used in each study in detail, but list them for each study in the tables reporting the statistical analysis (Tables 2A and 2B for the labor market studies, and Table 3 for the housing market studies). The reader will note that we also list other features of the ads that could affect the probability of a call-back - such as characteristics of the job or the apartment. We include these because - as explained in the next section - the statistical method is informed by differences in the coefficients between the two groups studied in any of the factors that can affect call-backs.

\section{Findings from the field experiments covered in this paper}

Table 1 summarizes the conventional results from the 10 studies we re-examine, as well as giving basic information about them, including the years covered, the groups covered, and the outcomes. The original studies report results in different ways, varying between chi-square/Fisher exact tests, binomial tests, or tests of the null hypothesis that there is no difference in the call-back rate between the groups, typically controlling for other aspects of the resumes. However, here we report results on a consistent basis for all studies - marginal effects from probit models using the full set of resume characteristics included in the data - which we have estimated from data provided by the authors of these studies. ${ }^{7}$

As reported in Table 1, the six labor market experiments covered in Panel A all find statistically significant evidence of discrimination against either ethnic minorities, blacks, or gays and lesbians. The estimated differentials by racial and ethnic groups are in the same range - an approximately 0.03 to 0.15 lower probability of a call-back. These are on somewhat different

\footnotetext{
${ }^{7}$ Details on the control variables, the standard errors, etc., are provided in tables discussed below. Not surprisingly, the results in Table 1 closely parallel the conclusions of the original papers - however they report their results - although they are not always identical.
} 
baseline rates of call-backs, but the call-back rates also do not vary that much across these studies. ${ }^{8}$ The two estimates from Drydakis (2014), for discrimination against gays and lesbians in Cyprus, are much larger (although the baseline call-back rates are much higher too).

The four housing market studies similarly find consistent evidence of discrimination against minorities. The range of estimates is fairly tight (a 0.09 to 0.17 lower call-back rate). Thus, every one of these studies points to evidence of discrimination against the minority group.

The conclusions from these studies strongly echo the broader literature, in which nearly every study finds evidence of discrimination in labor or housing market on the basis of race or ethnicity (Rich, 2014; Zschirnt and Ruedin, 2015; Neumark, 2016; Quillian et al., n.d.), as do the smaller number of studies of discrimination based on sexual orientation (Neumark, 2016). The question this paper addresses is whether this near-uniform evidence of discrimination from field experiments is an accurate reflection of discriminatory behavior, supporting a conclusion that discrimination really is this consistent and pervasive, or whether the evidence in at least some of these studies might reflect biases stemming from differences in the variance of unobservables across groups - the problem highlighted by the Heckman-Siegelman critique.

Some of the studies also include female and male applicants, or more broadly test for discrimination along multiple dimensions, including sex and age (Carlsson and Eriksson, 2014). We do not focus, in this paper, on evidence on discrimination based on sex or age. The broader literature focuses far more on race and ethnicity (and more recently on sexual orientation), and - as we have noted - delivers a near-uniform finding of discrimination against minorities. The evidence of sex discrimination is less robust, and tends to point less to discrimination against women, and

\footnotetext{
${ }^{8}$ One might wonder about apparent evidence of discrimination against British immigrants in Canada; indeed, we will see in implementing the correction for the Heckman-Siegelman critique below that this evidence appears to be spurious.
} 
more to the importance of sex norms for jobs in whether male or female applicants received more call-backs (Neumark, 2016). And recent evidence from a large-scale correspondence study of age discrimination yields ambiguous results for men, but not women (Neumark et al., 2016).

We next provide a brief discussion of the approach used to correct for the bias in estimates of discrimination from the standard field experiment design, and then present our re-examination of the data from the 10 studies we have identified that have the requisite data to implement the method in Neumark (2012) to correct the estimates for bias from differences in the variances of unobservables.

\section{Addressing the Heckman-Siegelman critique}

There are quite a few critiques of AC studies aside from the one we focus on here. Most of them are laid out in Heckman and Siegelman (1993), and discussed further in Neumark (2012) in the context of the framework laid out in this section. Some of the more important critiques - such as the possibility of "experimenter effects," and small differences between applicants that can matter a lot when applicants are matched on so many characteristics - can be addressed by using correspondence studies instead of audit studies, and indeed most recent research uses the correspondence study technique. The Heckman-Siegelman critique is of particular importance because it applies equally well to correspondence studies, even under otherwise ideal conditions such as no mean differences in unobservables between groups, but only differences in the variances of unobservables. And this critique is salient because nothing in the research design rules out differences in the variances of unobservables, and indeed - as noted earlier - these differences are foundational in models of statistical discrimination. We first lay out a basic framework for the analysis of data from an audit or correspondence study, and then explain the 
bias and the correction. ${ }^{9}$

Non-experimental regression-based approaches testing for and measuring discrimination use data on the groups in question in a population, introducing regression controls to try to remove the influence of group differences in the population that can affect outcomes (Altonji and Blank, 1999). Correspondence (and audit) studies, in contrast, create an artificial pool of labor market participants among whom there are supposed to be no average differences by group. This is clearly a potentially powerful strategy, because if we have, e.g., a sample of blacks and whites who are identical on average, because race is randomly assigned to a subset of similar resumes, then in a regression of the form

$$
Y=\alpha+\beta B+\varepsilon,
$$

where $Y$ is the outcome and $B$ is a dummy variable for blacks, $\varepsilon$ is uncorrelated with $B$, so that the OLS estimate $\hat{\beta}$ (or simply the mean difference in $Y$ ) provides an estimate of the effect of race discrimination on $Y .^{10}$

Of course, most of the earlier regression studies focus on wages, whereas AC studies focus on hiring. If an employer is free to pay a lower wage to blacks, for example, then in the context of the Becker employer discrimination model, why discriminate in hiring? One common interpretation is that there is an equal wage constraint - perhaps due to a minimum wage, or because anti-discrimination laws are more effective at rooting out wage discrimination than hiring discrimination. Alternatively, in the simple model, employers with stronger discriminatory tastes than the marginal employer will discriminate in hiring. As we make clear below, however, this framework does not only detect taste discrimination à la Becker.

\footnotetext{
${ }^{9}$ This section draws heavily on Neumark (2012), while avoiding many details that a reader can find in that paper.

${ }^{10}$ For simplicity, the discussion here is couched solely in terms of blacks and whites.
} 
To provide a more formal framework, suppose that productivity depends on two individual characteristics (standing in for a larger set of relevant characteristics), $X^{\prime}=\left(X^{I}, X^{I I}\right)$, so that productivity is $P\left(X^{\prime}\right) . X^{I}$ is what the firm observes, and $X^{I I}$ is unobserved by firms. It is simplest, for now, to think of $Y$ as continuous, such as the wage offered, although in fact in AC studies we should think of it as latent productivity leading to a decision to hire/call-back or not.

Define discrimination as

$$
Y\left(P\left(X^{\prime}\right), B=1\right) \neq Y\left(P\left(X^{\prime}\right), B=0\right) \text {. }
$$

Assume that $P(.,$.$) is additive, so$

$$
P\left(X^{\prime}\right)=\beta_{I} X^{I}+X^{I I},
$$

where the coefficient of $X^{I I}$ is normalized to one as it is unobservable, and

$$
Y\left(P\left(X^{\prime}\right), B\right)=P+\gamma B .
$$

Discrimination against blacks implies that $\gamma<0$, so that blacks are paid less than or perceived as less productive than whites who are actually equally productive.

In correspondence studies, researchers create resumes that standardize the productivity of applicants at some level. Denote expected productivity for blacks and whites, based on what the firm observes, as $P_{B}{ }^{*}$ and $P_{W}{ }^{*} . Y$ is observed for each tester, so each test - the outcome of applications to a firm by one black and one white tester/applicant - yields an observation

$$
Y\left(P_{B}{ }^{*}, B=1\right)-\mathrm{Y}\left(P_{W}{ }^{*}, B=0\right)=P_{B}{ }^{*}+\gamma-P_{W}{ }^{*} .
$$

Given that the correspondence study design sets $P_{B}{ }^{*}=P_{W}{ }^{*}$, we should be able to estimate $\gamma$ easily from these data, by simply running a regression of $Y$ on the dummy variable $B$ and a constant. (Some potential complications are discussed in Neumark, 2012).

A correspondence study can preclude systematic differences between groups in observables and experimenter effects. But there can still be assumed differences in means between 
groups despite the groups using matched resumes. In equation (5) above, $P_{B}{ }^{*}=\mathrm{E}\left(\beta_{I} X_{B}{ }^{I}+X_{B}{ }^{I I} \mid X_{B}{ }^{I}\right.$, $B=1$ ), and similarly for $P_{W}{ }^{*}$. Assuming randomization, and with $X_{B}{ }^{I}=X_{W}{ }^{I}=X^{I}$, the right-hand side of equation (5) reduces to $\gamma+\mathrm{E}\left(X_{B}^{I I} \mid X^{I}, B=1\right)-\mathrm{E}\left(X_{W}^{I I} \mid X^{I}, B=0\right)$, implying that we only identify $\gamma$ if $\mathrm{E}\left(X_{B}{ }^{I I} \mid X^{I}, B=1\right)=\mathrm{E}\left(X_{W}{ }^{I} \mid X^{I}, B=0\right)$. Employers may have different expectations about the mean of $X^{I I}$ for blacks and whites, conditional on what they observe, which a labor economist would label statistical discrimination. Although economists are interested in distinguishing between statistical and taste discrimination, both are illegal under U.S. law and both also appear to be illegal under European Union law. ${ }^{11}$ Moreover, it is challenging to distinguish between the two models. Thus, this issue is put aside, and the discrimination estimates from the studies considered in this paper interpreted as the sums of taste and statistical discrimination. ${ }^{12}$

That is not to suggest that researchers using AC methods have not tried to distinguish between taste and statistical discrimination. The idea exploited in most studies is that when the applications include a richer set of applicant characteristics, it is less likely that statistical discrimination plays much of a role in group differences in outcomes (e.g., Ewens et al., 2014).

\footnotetext{
${ }^{11}$ As discussed in Neumark (2016), the U.S. Code of Federal Regulations (29, § 1604.2) defines as illegal discrimination "The refusal to hire an individual because of the preferences of coworkers, the employer, clients or customers ..." But it also states "The principle of nondiscrimination requires that individuals be considered on the basis of individual capacities and not on the basis of any characteristics generally attributed to the group. There is not as explicit a prohibition of statistical discrimination in the European Union (EU). Article 2 of the EU's Directive 2000/43/EC prohibits both "direct" and "indirect" discrimination, but these appear to line up, respectively, with disparate treatment and disparate impact in the U.S. context (see http://eur-lex.europa.eu/legal-content/en/ALL/?uri=CELEX\%3A32000L0043, viewed December 2, 2015). However, other material suggests that statistical discrimination is covered by direct discrimination (OECD, 2013, p. 195).

${ }^{12}$ Indeed, it seems that we could also include implicit discrimination (e.g., Bertrand et al., 2005). Implicit discrimination posits a different reason for undervaluing the productivity of a group of workers, which can lead to different policy levers to combat it. But if it arises when employers evaluate applicants in AC studies, the empirical implication for the framework developed here would likely be the same as the implication of taste discrimination.
} 
Effectively, one tries to eliminate the term $\mathrm{E}\left(X_{B}{ }^{I I} \mid X^{I}, B=1\right)-\mathrm{E}\left(X_{W}{ }^{I I} \mid X^{I}, B=0\right)$ from the estimated difference in hiring rates to see how much of the overall difference in hiring rates is accounted for by this difference in expectations, which corresponds to statistical discrimination. ${ }^{13}$

Oreopoulos (2011) and Ewens et al. present perhaps the most thorough attempts at discerning between these hypotheses about discrimination in AC studies. Oreopoulos uses the approach of adding information (e.g., on country of education, to signal English language skills) to see whether estimated hiring gaps fall, as well as examining differences in hiring gaps for occupations across which the importance of statistical discrimination likely varies. In many cases, he does not find evidence consistent with statistical discrimination, despite evidence from a survey of participating employers that they used name, or country of education or experience, as a signal of potential language problems.

Ewens et al. (2014) specifically allow for the mean and variances of unobservables to differ across groups (as in Aigner and Cain, 1977), and examine whether the differential treatment by race is more consistent with statistical discrimination (both first- and second-moment) or tastebased discrimination. Although they do not correct for differences in variances of unobservables, they demonstrate that group differences in outcomes may decrease when more information is provided and they argue that the evidence is consistent with statistical discrimination. In particular, they demonstrate that the differences in outcomes across groups vary with the differences in racial composition across neighborhoods in a way that is consistent with the hypothesized differences in variances of unobservables across groups.

One could presumably use the method described below for resumes with varying amounts of information, to recover unbiased estimates under different information treatments and hence try

\footnotetext{
${ }^{13}$ Neumark (2016) provides many examples, and also some criticisms of this approach.
} 
to gauge the relative importance of taste and statistical discrimination. However, this issue is not the focus of our analysis in this paper. Instead, our focus is re-examining the 10 studies identified earlier and investigating whether the uniform evidence of discrimination from these studies persists once account is taken of the Heckman-Siegelman critique.

The issue raised by the Heckman-Siegelman critique arises from the potential for differences across groups in the variances of the unobservables - which is equally problematic even in the ideal condition of no assumed mean difference. To see how the difference in variances can drive differences in the results of the analysis of data from an AC study, it is most natural to think of equation (1) as a latent variable model for productivity, with applicants having to exceed some productivity threshold with sufficiently high probability (where $\alpha$ in equation (1) can also include observables that vary across individuals that affect productivity, which we have denoted $\left.X^{I}\right)$.

To isolate the problem, consider the best-case scenario where $\mathrm{E}\left(X_{B}{ }^{I I} \mid X^{I}, B=1\right)=\mathrm{E}\left(X_{W}{ }^{I I} \mid X^{I}\right.$, $B=0$ ) - i.e., there is no statistical discrimination regarding levels. But the standard deviations of the unobservables, denoted $\sigma_{B}{ }^{I I}$ and $\sigma_{W}{ }^{I I}$, need not be equal. ${ }^{14}$

Assume the applicant is called back (hired) if there is a sufficiently high probability that their productivity exceeds a given threshold. In this case, the inequality $\sigma_{B}{ }^{I I} \neq \sigma_{W}{ }^{I I}$ combined with the design of AC studies results in a biased estimate of discrimination; worse, we cannot necessarily even sign the bias.

To see the intuition, recall that the key feature of the usual design of AC studies is using similar resumes on the applicants in different groups. This requires choosing a particular level of

\footnotetext{
${ }^{14}$ Neumark assumes homoscedasticity within groups, and thus suppresses conditioning on $X_{B}{ }^{I}$ and $X_{W}^{I}$.
} 
the quality of the resumes. Suppose, for example, that the research design standardizes $X^{I}$ at a low level, denoted $X^{I^{*}}$. Employers care about how likely it is that the sum $\beta_{I} X^{I}+X^{I I}$ exceeds some threshold. Given the low value $X^{I^{*}}$, this is more likely for a group with a high variance of $X^{I I}$. Thus, even in the case of no discrimination $(\gamma=0)$, the employer will favor the high-variance group. Conversely, if standardization is at a high level of $X^{I^{*}}$, the employer will favor the lowvariance group. Because researchers do not have information on the population of real applicants to the jobs studied, there is no definitive way to know whether $X^{I^{*}}$ is high or low relative to the actual distribution, and hence no way to sign the bias. As discussed in more detail below, note that the variances of unobservables affect which group gets more call-backs only because of the research design standardizing the resumes at a particular level (when the level of standardization is not at the central tendency of the distribution).

The technique developed in Neumark (2012) to correct for the bias from differences in the variances of unobservable characteristics relies on the experimental study having extra information that explores the impact of different productivity or quality characteristics (creating applicants who have different levels of qualifications, for example). As long as some of these characteristics have the same effects in the latent variable model for the probability of an offer the key identifying assumption - this extra information allows the effect of the difference in variances between the groups' unobserved characteristics on the responses to be isolated from the role of discrimination in evaluating applicants. That is, it allows separate identification of the relative variances in the unobservables and the discrimination coefficient, $\gamma^{15}$

It is rare that correspondence studies include variables that shift the call-back probability,

\footnotetext{
${ }^{15}$ To reiterate, for the purposes of simplification, it is assumed $\mathrm{E}\left(X_{B}{ }^{I I} \mid X^{I}, B=1\right)=\mathrm{E}\left(X_{W}{ }^{I I} \mid X^{I}, B=0\right)$. Without this assumption, references to $\gamma$ in the remainder of this section should be read as references to $\gamma+\mathrm{E}\left(X_{B}^{I I} \mid X^{I}, B=1\right)=\mathrm{E}\left(X_{W}^{I I} \mid X^{I}, B=0\right)-$ i.e., the sum of taste and statistical discrimination.
} 
because these studies typically create one "type" of applicant for which there is only random variation in characteristics that are not intended to affect outcomes. However, the 10 studies discussed in Section 2 have this information - as in Bertrand and Mullainathan (2004), whose data Neumark (2012) used to illustrate this method for correcting for the bias in AC studies. Applying this method to the studies re-examined in this paper therefore allows us to determine whether the measures of discrimination from conventional analyses of the data in these studies provided unbiased estimates of discrimination, or instead either overstated or understated discrimination. ${ }^{16}$

The intuition behind the solution stems from the fact that a higher variance for one group (say, whites) implies a smaller effect of observed characteristics on the probability that a white applicant meets the standard for hiring. Thus, information from a correspondence study on how variation in observable qualifications is related to call-backs can be informative about the relative variance of the unobservables, and this, in turn, can identify the effect of discrimination. Based on this idea, the identification problem identified by the Heckman-Siegelman critique is solved by invoking an identifying assumption - specifically, that the effect of applicant characteristics that affect perceived productivity and hence call-backs have equal effects across groups - along with the testable requirement that some applicant characteristics affect the call-back probability (since if all the effects are zero we cannot learn about $\sigma_{B}^{I I} / \sigma_{W}^{I I}$ from these coefficient estimates).

In a probit specification, for example, we know that we can only identify the coefficients of the latent variable model for productivity relative to the standard deviation of the unobservable. In this case, we effectively have two probit models, one for blacks and one for whites. If we normalize $\sigma_{W}{ }^{I I}$ to one, then for a characteristic $(Z)$ that affects the call-back rate, we identify its

\footnotetext{
${ }^{16}$ For recent code to implement the estimator, we direct readers to the code used in Neumark et al. (2016), on the website of the American Economic Review (click on "Data Set" on the webpage at https://www.aeaweb.org/articles?id=10.1257/aer.p20161008).
} 
coefficient $\left(\delta_{W}\right)$ relative to $\sigma_{W}^{I I}$, or $\delta_{W} / \sigma_{W}{ }^{I I}$. However, if we assume that $\delta_{W}=\delta_{B}$, then we do not need to impose the normalization that $\sigma_{B}{ }^{I I}=1$, but instead can identify $\sigma_{B}{ }^{I I} / \sigma_{W}{ }^{I I}$ from the ratio of the coefficients on $Z$ in the probit for whites versus blacks, which in turn allows us to identify $\gamma$. The estimation can be done using a heteroscedastic probit model. Finally, when there are multiple productivity-related characteristics that shift the call-back probability $Z_{k}(k=1, \ldots, K)$, there is an overidentification test because the ratio of coefficients on each $Z$, for whites relative to blacks, should equal $\sigma_{B}{ }^{I I} / \sigma_{W}{ }^{I I} .{ }^{17}$

The heteroscedastic probit model estimates can be decomposed into the estimated differential due to differences in $\gamma$, and the estimated differential due to differences in the variance of the unobservables. In generic notation, let the latent variable depend on a vector of variables $S$ and coefficients $\psi$, and the variance depend on a vector of variables $T$, which includes $S$, with coefficients $\theta$. The elements of $S$ are indexed by $k$. For a standard probit model, coefficient estimates are translated into estimates of the marginal effects of a continuous variable $S$ using

$$
\partial P(\text { call-back }) / \partial S_{k}=\psi_{k} \phi(S \psi)
$$

where $S_{k}$ is the variable of interest with coefficient $\psi_{k}, \phi($.$) is the standard normal density, and the$ standard deviation of the unobservable is normalized to one. Typically, this is evaluated at the means of $S$. When $S_{k}$ is a dummy variable such as race, the difference in the cumulative normal distribution functions is often used instead, although the difference is usually trivial.

The marginal effect is more complicated in the case of the heteroscedastic probit model, because if the variance of the unobservable differs by race, then when race "changes” both the

\footnotetext{
${ }^{17}$ Indeed, the identifying restriction $\delta_{W}=\delta_{B}$ only has to hold for subsets of the characteristics that shift the call-back probability, and one can rely only on this subset if the overidentification test for a larger set of resume characteristics fails (see Neumark, 2012).
} 
variance and the level of the latent variable that determines hiring can shift. As long as we use the continuous version of the partial derivative to compute marginal effects from the heteroscedastic probit model, there is a unique decomposition of the effect of a change in a variable $S_{k}$ that also appears in $T$ into these two components. In particular, denoting the variance of the unobservable [ $\exp (T \theta)]^{2}$, with the variables in $T$ arranged such that the $k^{t h}$ element of $T$ is $S_{k}$, then the overall partial derivative of $P$ (call-back) with respect to $S_{k}$ is

$$
\partial P / \partial S_{k}=\phi(S \psi / \exp (T \theta)) \cdot\left\{\psi_{k} / \exp (T \theta)\right\}+\phi(S \psi / \exp (T \theta)) \cdot\left\{\left(-S \psi \cdot \theta_{k}\right) / \exp (T \theta)\right\} .{ }^{18}
$$

The first part of the sum in equation (7) is the partial derivative with respect to changes in $S_{k}$ affecting only the level of the latent variable - corresponding to the counterfactual of $S_{k}$ changing the valuation of the worker without changing the variance of the unobservable. The second part is the partial derivative with respect to changes via the variance of the unobservable. In the analysis below, these two separate effects are reported as well as the overall marginal effect, and standard errors are calculated using the delta method. ${ }^{19}$

This discussion raises the issue of what we are trying to measure in audit and correspondence studies. Focusing on $\gamma$, the structural effect of race, captures the potential discounting by employers of black workers’ productivity à la Becker (and possibly statistical discrimination about the mean of $X^{I I}$ ). But as shown, employers could treat blacks and whites differently in hiring because of different variances of the unobservable. If the latter is accepted as

\footnotetext{
${ }^{18}$ See Cornelißen (2005).

${ }^{19}$ Because the formula for the derivative based on a continuous variable yields this unique decomposition, it is used below - and also to interpret the simple probit estimates, as in Table 1. The implied partial derivatives from the probit using the formula for a discrete variable (or computing the partial derivative for each sample observation and averaging, as is now more standard) were very similar. One can decompose the partial derivative from the heteroskedastic probit model based on the partial derivative for discrete variables calculated from difference in the cumulative normal distribution functions, but then the decomposition is not unique.
} 
a meaningful measure of discrimination, we might not want to eliminate it.

There are two reasons why the coefficient $\gamma$ is the focus of interest. First, to the best of our knowledge, differential treatment based on assumptions (true or not) about variances have not been viewed as discriminatory in the legal literature. Second, and probably more important, the taste discrimination (and possibly “first-moment” statistical discrimination) that correspondence studies capture in $\gamma$ generalizes from the correspondence study to the real economy. In contrast, the difference in treatment based on differences in the variances of unobservables is an artifact of the design of correspondence (or audit) studies - in particular, the standardization of applicants to particular, and similar, values of the observables, relative to the actual distribution of observables among real applicants. If, instead, a study used applicants that replicated the actual distribution of applicants to the employers in the study, there would be no bias - in the setting described here from different variances of the unobservables. This is discussed in detail in Neumark (2012).

That is not to say, however, that there cannot be discrimination based on second moments with, for example, risk averse firms. In that sense, one can potentially interpret the bias correction and decomposition not as separating out real versus spurious discrimination, but rather firstmoment versus second-moment discrimination. We could imagine, for example, that risk-averse firms are less likely to call back (or hire) workers with more uncertain productivity, even when on average they are as productive as another group. However, the potential difficulty with this interpretation is that we do not uniformly find that the minority group that experiences discrimination according to the conventional analysis generally has a higher variance of the unobservable; indeed, in both the labor market studies and the housing market studies we analyze, this is the case in just about half of the estimates. This is a further reason why, in the remainder of the paper, we interpret the evidence as isolating discrimination by adjusting for differences in the variances of unobservables. 


\section{Results from re-examination of field experiments with quality variation across resumes}

\section{Labor market field experiments}

We report the results for the re-analysis of the datasets from the labor market field experiments in Tables 2A and 2B. Turning to the first set of labor market studies covered in Table $2 \mathrm{~A}$, we first report the estimated discrimination coefficient ( $\gamma$, in the equations from above) in the

first row of the table (Panel A). These match the estimates in the last column of Table 1, and have already been summarized.

Panel B turns to the heteroscedastic probit estimates that correct for biases from differences in the variance of unobservables. The "Controls" entry toward the bottom of the table lists the resume characteristics including those likely to shift the call-back rate (like education, skills, etc.). ${ }^{20}$ The first row of Panel B reports the overall effect from the heteroscedastic probit estimates. These are similar to the probit estimates. The next two rows of the table report the key results from the decomposition of the heteroscedastic probit estimates. The "level" effect (labelled "Marginal effect through level (unbiased)" in the table) is the unbiased estimate, and the "variance” effect reflects the bias from correspondence study design, arising because of the interaction between the quality of the resumes sent out (relative to the actual distribution) and differences in the variances of unobservables.

Looking at these estimates, for the first study - the Baert et al. (2015) experiment on discrimination against Turkish job applicants relative to natives in Belgium - the evidence of

\footnotetext{
${ }^{20}$ Some studies include resume characteristics that are not independent of minority group status. For example, Oreopoulos (2011) indicates, for some of his ethnic groups, that some education or experience occurred in a foreign country. This is useful for asking what might explain variation in the amount of discrimination immigrants face, which is the focus of his study. But it does not fit into the narrower question considered in this paper of discrimination against the minority group per se. Hence, we only use resume characteristics that are constructed to be orthogonal to minority group status.
} 
discrimination completely disappears in the heteroscedastic probit estimates. In both columns (1) and (2) - the first for a call-back, and the second for an immediate interview - the negative and significant coefficient estimate on the indicator for Turkish applicants becomes positive and statistically insignificant.

In contrast, the estimated effect through the variance is negative and significant, implying that the study design generates bias towards finding evidence of discrimination. The next row of the table reports that the ratio of the estimated standard deviations of the unobservables for minority versus non-minority candidates is around 0.5 , indicating a lower variance of unobservables for the Turkish applicants. In terms of the model, the reduction in estimated discrimination coupled with a lower variance of unobservables for minorities implies that on average the resumes in this study were of relatively low quality compared to what employers see; thus, the low variance group is less likely to be of sufficiently high quality on the unobservables to merit a call-back, and the difference in variance creates a bias towards finding discrimination against Turkish applicants.

Below the decomposition estimates, the table reports some additional diagnostic test results. First, it reports the p-value from the overidentification test that the ratios of the skill coefficients between (in this case) Turkish and native applicants are equal across all of the skills/resume characteristics. The p-value is 0.97 in column (1) and 0.93 in column (2), indicating that we do not reject the overidentifying restrictions. On the other hand, in this case, as reported in the next row, the data tend to reject the restriction to the homoscedastic specification; the p-value from a likelihood ratio test is 0.01 in column (1) and 0.10 in column (2). The final test result reported is whether the ratio of variances of the unobservables equals one; this is rejected strongly in both columns (a result we expect would to parallel to some extent the likelihood ratio test).

Thus, for the Baert et al. study, application of this method of correcting for bias from 
differences in the variances of unobservables very much overturns the evidence of ethnic discrimination. There is one additional point to make with reference to the more general earlier discussion about interpreting the effect through the variance. One might refer to the negative (and significant) estimates on "Marginal effect through variance" as suggesting that the evidence of discrimination has not gone away, but simply been "displaced” to show up in the variance. We have already explained why, in the context of the method and underlying model used in this paper, the estimated effect through the variance is an artifact of the study, and would not be expected to be replicated in the real world. Similarly, it would not be replicated if the study had used highquality resumes, or a distribution of resumes that matched the distribution employers actually see. An alternative hypothesis, though, is that the effect of variance is real, and reflects employer risk aversion rather than how the employer evaluates the likelihood that an applicant exceeds a callback/hiring threshold, given the resume. However, if there is risk aversion, then high-variance groups would be penalized. That is inconsistent with the evidence from the Baert et al. data, since the minority applicants are estimated to have lower variance. ${ }^{21}$

Having gone through the results for the first study in detail, the results for the other labor market studies can be covered more succinctly. The Carlsson and Rooth (2007) study of discrimination against Middle Easterners in Sweden asks a very similar question to Baert et al. (2015). In this case, however, the conclusions are scarcely affected by addressing the HeckmanSiegelman critique. The estimated marginal effect through the level $(-0.102)$ is very similar to the simple heteroscedastic probit estimate $(-0.095)$, and the estimated marginal effect through the

\footnotetext{
${ }^{21}$ This may be too strong a statement, since if employers actually evaluate applicants based on their assumed variance of the unobservable, the statistical model might be different. We are not aware of any field experiments that have tried to incorporate risk aversion, although this might be fruitful. Dickinson and Oaxaca (2009) provide a lab experiment study of this type of discrimination in labor markets.
} 
variance is close to zero (0.007) and estimated precisely. In this case the ratio of the estimated standard deviations of the unobservable for minorities relative to non-minorities is very close to one (1.03), which implies - in terms of the Heckman-Siegelman critique - that there is unlikely to be any bias regardless of the quality of the artificial resumes relative to the population of resumes that the employer sees, which is consistent with the robustness of the evidence for this study. Note also that the data do not reject the overidentifying restrictions, nor do they reject the restriction to the homoscedastic model or that the ratio of standard deviations equals one - not surprising given the estimates.

The Drydakis (2014) study looks at discrimination against gays and lesbians. In this study, also, correcting for potential bias from differences in the variances of the unobservables does not alter the conclusion much. Indeed, the estimated effect of being gay or lesbian is larger negative $(-0.476$ or -0.499$)$ after correcting for this bias, relative to the overall effect of -0.384 for gays and -.304 for lesbians. For both groups, the estimated variance of the unobservable is quite a bit larger than for straight men or women, with a ratio of standard deviations of 1.59 for gay versus straight men, and 2.27 for lesbian versus straight women. The combination of a higher variance for gays or lesbians with a larger estimate of discrimination would imply that the resumes were of low quality relative to the distribution, which would lead employers to favor the high variance group and generate a bias towards zero in the estimate of discrimination.

Note that for the Drydakis analyses there is strong evidence against the homoscedastic probit model and marginally significant evidence against equal standard deviations. Also, for the analysis of gay versus straight men the overidentifying restrictions are rejected at the 10-percent level. This last result prompted us to estimate a less restrictive model that did not restrict the effects of two of the resume characteristics to be the same across gay and straight men - chosen based on the estimates indicating that these interactions did not fit the expected pattern if the 
coefficients in the latent variable model were equal and only the variances of the unobservables varied. ${ }^{22}$ In this case the overidentification restrictions were no longer rejected (the p-value was 0.751), yet the estimates were very similar to those reported in column (5) of Table 2A.

Lee and Khalid (2016) study discrimination against Malays (versus Chinese), in the private sector in Malaysia. ${ }^{23}$ In this case, the conclusions are dramatically affected by addressing the Heckman-Siegelman critique, as the estimated marginal effect through the level changes sign and becomes significant and positive - consistent with discrimination in favor of Malays. ${ }^{24}$ In contrast, the estimated marginal effect through the variance is large, negative, and significant $(-0.445)$. In this case the ratio of the estimated standard deviations of the unobservable for Malays relative to Chinese is very low (0.11). The combination of a lower variance for Malays with a smaller (indeed, opposite-signed) estimate of discrimination would imply that the resumes were of low quality relative to the distribution for jobs included in the study, which would lead employers to favor the high variance group and generate a bias towards discrimination in favor of Chinese applicants. Note also that the data do not reject the overidentifying restrictions.

\footnotetext{
22 These were the indicators for a high-quality resume (more experience) and for resume type. These were chosen because the estimated signs of the interactions relative to the signs of the main effects were rather strongly inconsistent with what would be predicted based on the higher estimated variance of the unobservable for gays. Note that the model is identified as long as the effects of some variables that shift the call-back probability are restricted to be equal across the two groups; this restriction does not have to hold for all of them, and can be relaxed by adding interactions between the group indicator and the resume characteristic to the heteroscedastic probit model.

${ }^{23}$ Malays are not the minority group, although we retain that label in the table to be consistent with other studies. Lee and Khalid (2016) discuss issues related to potential discrimination against Malays in the private sector, including affirmative action for Malays in public education that may lead Malay graduates to be less preferred. Their sample size with controls is a bit smaller than ours (see their Table 4), because they also include data on the companies in the study; these data are not always available, and the company data were not provided to us.

${ }^{24}$ While this change in results is striking, there are also findings in the Lee and Khalid paper that do not cleanly fit the expected story of discrimination against Malays. In particular, they find stronger anti-Malay discrimination in hiring for private university graduates, where affirmative action in education is not implemented.
} 
Turning to the remaining labor market studies, in Table 2B, Oreopoulos (2011) studies outcomes for six immigrant groups relative to native Canadians. It turns out that for two of these groups - Chinese and Indian - the evidence of discrimination remains significant after addressing the Heckman-Siegelman critique, and is actually stronger, with estimates changing from around -0.05 to -0.10 or greater. For both groups, the estimated variance of the unobservable is larger for immigrants than for natives, which appears to interact with the applicants being low quality so that the higher variance biases the estimate of discrimination from the standard probit towards zero. In contrast, for the other four groups - Chinese-Canadian, ${ }^{25}$ Pakistani, Greek, and British - there is no longer significant evidence of discrimination. Note that in two cases - Pakistani and Greek the point estimate of the marginal effect of minority group membership through the level is still a large negative number, but is insignificant. In contrast, for the British, the point estimate is no longer negative.

Turning to the other diagnostics, in every case for the Oreopoulos analysis, the overidentification restrictions are not rejected. Similarly, with the exceptions of the analysis for the Chinese applicants, the data do not reject the restriction to the homoscedastic model. Thus, in this case we are sometimes failing to find evidence of discrimination because we are estimating a more flexible model even when the data do not reject a more restrictive model that provides evidence of discrimination - and the results for the Pakistani and Greek applicants are notable in this regard. This poses the usual trade-off of bias versus precision, although generally speaking labor economists are willing to estimate less restrictive models that eliminate bias at the risk of decreased precision. Regardless, it seems reasonable to conclude that the re-analysis of the Oreopoulos data indicates far less robust evidence of discrimination than the original study.

\footnotetext{
${ }^{25}$ This refers to an English first name and a Chinese last name.
} 
Finally, column (7) of Table 2B repeats the re-analysis of the Bertrand and Mullainathan (2004) data from Neumark (2012). In this case, the evidence of discrimination gets a bit stronger, and the variance of the unobservable is estimated to be larger for blacks. These findings are consistent with low quality resumes generating a bias against finding discrimination, although the qualitative conclusions are unchanged.

Thus, the conclusion from our re-examination of the labor market experiments is that the findings from the existing studies of discrimination against ethnic, racial, or sexual orientation minorities are not always robust to addressing the Heckman-Siegelman critique. All 14 estimates based on the existing studies, using the conventional approach, point to evidence of discrimination. But only six (or just under one-half) of the corrected estimates provide evidence of discrimination. ${ }^{26}$

This conclusion that the analysis of data from field experiments on labor market discrimination is not always robust is echoed in the findings reported in Neumark et al. (2016). They study age discrimination in hiring, and find that the evidence of discrimination against older women is robust to addressing the Heckman-Siegelman critique, but the evidence of discrimination against older men is not robust. On the other hand, some other recent papers using this technique do not find large differences. Carlsson et al. (2013) re-examine data from four previous studies of the Swedish labor market, each of which includes some form of the data required to implement the bias correction. Their re-analysis does not lead to large changes in the estimates of discrimination, although sometimes the estimated discrimination (against those with Arabic names, and in favor of women) becomes smaller. Three recent studies by Baert, all on the

\footnotetext{
${ }^{26}$ This includes the evidence from Carlsson and Rooth (2007), Drydakis (2014, for both gays and lesbians), Oreopoulos (2011, for Chinese and Indian), and Bertrand and Mullainathan (2004, significant at 10-percent level).
} 
Belgian labor market, found no change in the estimates of discrimination in these experimental studies. Baert (2015) implemented this method in a study of discrimination against Turkish school-leavers in Belgium, using information on distance from the worker's residence to the workplace and other application characteristics to identify the heteroscedastic probit model, and report that this correction does not alter the conclusions. Baert (2014) applied the bias correction in an investigation of discrimination based on sexual orientation and family responsibilities, and found no bias or difference in reported results (Baert, 2014, footnote 15, p. 551). Baert (2016) found similar results in a study of hiring discrimination against disabled individuals (see pp. 8384). Nunley et al. (2015) studied racial discrimination in hiring of recent college graduates in the United States. Applying the bias correction to their finding of a significant, lower interview rate to black graduates indicated that the baseline estimate of discrimination was understated, although the resulting estimated marginal effects through the level and variance were not statistically significant (p. 1118). Thus, among these latter studies, there is again sometimes an indication that the results are not robust to addressing the Heckman-Siegelman critique, although there is less clear of an indication that ignoring this critique leads to overstating discrimination.

\section{Housing market field experiments}

The results from the re-examination of the evidence from the housing discrimination studies are presented in Table 3. Ahmed et al. (2010) study discrimination against Arab applicants in Sweden, looking - as three of the four housing studies do - at both positive responses and offers of immediate showings. In this study, correcting for potential bias from differences in the variances of the unobservables does very little to change the conclusions. The estimates of lower positive responses or offers of immediate showings to Arab applicants become if anything more negative - most notably for immediate showing, where the estimate changes from -0.074 to -0.146 - and both estimates are statistically significant. The estimated effects of Arab ethnicity 
through the variance are positive, and larger for immediate showings, corresponding to the larger negative estimate on the marginal effect through the level. The estimated variance of the unobservable is larger for Arab applicants, so combined, the estimates imply that the applications were lower quality than the population of applications to these landlords, biasing towards zero the conventional probit estimate of discrimination in immediate showings. Turning to the other diagnostics, in neither analysis are the overidentification restrictions, the restriction to a homoscedastic probit model, or equality of the standard deviations rejected. Thus, in this study evidence of discrimination persists.

These same conclusions are echoed in the remaining columns of the table - for the Bosch et al. (2010), Carlsson and Eriksson (2007), and Ewens et al. (2014) studies. In all cases, the biascorrected estimates still lead to statistically significant evidence of discrimination based on race and ethnicity. And in most cases the point estimate for the marginal effect through the level is very close to the overall heteroscedastic probit estimate, while the estimates of the effect of race or ethnicity through the variance are very small. ${ }^{27}$

There is one case (Ewens et al., 2014) where the overidentifying restrictions are rejected at the 10-percent level (and the p-values for the other tests are fairly low). We therefore carried out an additional analysis, paralleling what we did with the Drydakis (2014) data on gay and straight male applicants. In this case, we estimated a less restrictive model that did not restrict the effects of percent black in the area or city to be the same across black and white applicants, based on the

\footnotetext{
${ }^{27}$ One reason for the robustness of the results in Carlsson and Eriksson (2013) could be because they use applications with substantial variation in applicant characteristics. The authors do this because by avoiding standardizing applicants to a very narrow range, the bias identified by the Heckman-Siegelman critique can be reduced, although this cannot ensure that the range of quality of actual applicants is not larger. It is also the case that - especially for the positive response outcome - the variances are nearly equal (the ratio of estimated standard deviations is 1.02), so that using a narrow range of applicant quality would not introduce bias.
} 
estimates indicating that these interactions did not fit the pattern of equal coefficients in the latent variable model with probit coefficient differing because of differences in the variances of unobservables. In this case the overidentification restrictions were no longer rejected (the p-value was 0.877 ), yet the conclusions were similar to those in column (7) of Table 3. The overall estimate (standard error) of discrimination from the heteroscedastic probit model was -0.064 (0.023), and the unbiased estimated effect through the level was $-0.067(0.023)$.

Thus, the conclusion from our re-examination of the housing market studies is that the findings from the existing studies of discrimination against ethnic or racial minorities are robust to addressing the Heckman-Siegelman critique. With one minor exception, these past studies found evidence of discrimination, and our corrected estimates are qualitatively and usually quantitatively very similar.

Why might the housing market tests of callback for rental enquiries be more robust to addressing the Heckman-Siegelman critique? One possibility is that that the information provided in the housing market tests is sufficiently complete that there is little scope for a role for unobservables, and hence little impact of any differences in the variance of unobservables across groups. In housing markets, there may not be much more that matters to agents than ability to pay, and the information in the applications may convey this quite reliably. In contrast, an employer has an ongoing relationship with a worker, as do the employer's customers, so that many factors that are not conveyed in an on-line job application could potentially weigh on an employer's decision, and hence, correspondingly, differences in the variances of these unobserved factors across groups could matter much more.

\section{Conclusions}

The goal of this paper was to re-examine evidence from field experiments on labor market and housing market discrimination (experiments that, in general, identify the combined effect of 
taste discrimination and statistical discrimination). Specifically, our goal is to see if the nearuniform findings of discrimination against minorities hold up after correcting for an important source of bias originally identified in Heckman and Siegelman (1993) - which we refer to as the “Heckman-Siegelman critique.” This critique emphasises that even under quite ideal conditions for these studies, the evidence can be biased in either direction - or, equivalently, discrimination can be unidentified - if the variances of the unobservables differ across the groups studied. This is a plausible concern, given that a difference in the variances of unobservables across groups cannot be cannot be ruled out and indeed is at the core of early theoretical models of statistical discrimination (Aigner and Cain, 1977). We re-examine evidence from 10 studies that have the requisite data - applicant or other characteristics aside from the identifier for the group in question which shift the probability of call-backs or hires - implementing a correction for this bias proposed in Neumark (2012).

We find that for the housing market studies, the estimated effect of discrimination is robust to this correction. For the labor market studies, in contrast, the evidence is less robust; in about half of cases the estimated effect of discrimination either falls to near zero or becomes statistically insignificant, and in one case the sign changes.

We of course cannot definitively extrapolate from the 10 studies we were able to reexamine to the broader set of field experiments on discrimination by race, ethnicity, and sexual orientation. However, given that about half of the estimates of labor market discrimination that we could re-examine no longer provide statistical evidence of discrimination (or discrimination in the same direction) after correcting for bias from differences in the variance of unobservables, it seems reasonable to suggest that the overall (and overwhelming) evidence of labor market discrimination from field experiments is likely less robust than it seems. We have no doubt that in many countries there is discrimination in labor and housing markets against many groups, and that 
- like the subset of studies we re-examine in this paper - the evidence of discrimination would frequently be robust to addressing the Heckman-Siegelman critique. But our evidence also indicates that in some cases a research design that enables a researcher to address this critique would not find evidence of labor market discrimination.

If nothing else, this conclusion implies that we need three types of research to draw more definitive conclusions from field experiments on labor and housing market discrimination: (1) more evidence using this kind of research design and methods; (2) more analysis of how best to implement these methods, what kinds of quality shifters provide the most informative estimates, etc.; and (3) further consideration of whether there are other ways to address the HeckmanSiegelman critique and whether they generate similar answers. Moreover, given the nonrobustness of the experimental evidence on labor market discrimination, in particular, to addressing the Heckman-Siegelman critique, one could reasonably argue that future experimental studies of labor market discrimination (and perhaps of discrimination in any market) must take account of this critique to be regarded as credible. 


\section{References}

Ahmed, A., Andersson, L. and Hammarstedt, M. (2010). 'Can discrimination in the housing market be reduced by increasing the information about the applicants?', Land Economics, 86(1), pp. 79-90.

Aigner, D. and Cain, G. (1977). 'Statistical theories of discrimination in labor markets', Industrial and Labor Relations Review, 30(2), pp. 175-87.

Altonji, J. and Blank, R. (1999). 'Race and gender in the labor market'. In Handbook of Labor Economics, Volume 3, edited by Orley C. Ashenfelter and David Card, 3143-259. Amsterdam: Elsevier.

Baert, S. (2014). 'Career Lesbians. Getting Hired for Not Having Kids?' Industrial Relations Journal, 45, pp. 543-561.

Baert, S. (2015). 'Field experimental evidence on gender discrimination in hiring: Biased as Heckman and Siegelman predicted?', Economics, 9, August 20, http://dx.doi.org/10.5018/economics-ejournal.ja.2015-25.

Baert, S. (2016). 'Wage Subsidies and Hiring Chances for the Disabled: Some Causal Evidence', European Journal of Health Economics, 17, pp. 71-86.

Baert, S. and Balcaen, P. (2013). 'The Impact of Military Work Experience on Later Hiring Chances in the Civilian Labour Market. Evidence from a Field Experiment'.

Economics: The Open-Access, Open-Assessment E-Journal, 7, http://www.economicsejournal.org/economics/journalarticles/2013-37.

Baert, S., Cockx, B., Gheyle, N. and Vandamme, C. (2015). 'Is there less discrimination in occupations where recruitment is difficult?', Industrial and Labor Relations Review, 68(3), pp. 467-500.

Baert, S. and Verhofstadt, E. (2015). 'Labour market discrimination against former juvenile delinquents: Evidence from a field experiment', Applied Economics, 47, pp. 1061-72.

Bertrand, M., Chugh, D., and Mullainathan, S. (2005). 'Implicit discrimination', American Economic Review Papers and Proceedings, 95(2), pp. 94-8.

Bertrand, M. and Mullainathan, S. (2004). 'Are Emily and Greg more employable than Lakisha and Jamal? A field experiment on labor market discrimination', American Economic Review, 94(4), pp. 991-1013.

Bosch, M., Carnero, M. and Farré, L. (2010). 'Information and discrimination in the rental housing market: Evidence from a field experiment', Regional Science and Urban Economics, 40(1), pp. 11-19.

Carlsson, M. and Eriksson, S. (2014). 'Discrimination in the rental market for apartments', Journal of Housing Economics, 23, pp. 41-54.

Carlsson, M., Fumarco, L. and Rooth, D.-O. (2013). 'Artifactual evidence of discrimination in correspondence studies? A replication of the Neumark method', IZA Discussion Paper No. 7619. Bonn, Germany: IZA.

Carlsson, M. and Rooth, D.-O. (2007). 'Evidence of ethnic discrimination in the Swedish labor market using experimental data', Labor Economics, 14(4), pp. 716-29.

Cornelißen, T. (2005). 'Standard errors of marginal effects in the heteroskedastic probit model', Institute of Quantitative Economic Research, Discussion Paper No. 230. Hanover, Germany: University of Hanover.

Dickinson, D. and Oaxaca, R. (2009). 'Statistical discrimination in labor markets: An 
experimental analysis', Southern Economic Journal, 71(1), pp. 16-31.

Doleac, J. Stein. L.C.D. (2013). 'The Visible Hand: Race and Online Market Outcomes', Economic Journal, 123(572), pp. F469-92.

Drydakis, N. (2014). 'Sexual orientation discrimination in the Cypriot labor market: Distastes or uncertainty?’ International Journal of Manpower, 35(5), pp. 720-44.

Ewens, M., Tomlin, B. and Wang, L.-C. (2014). 'Statistical discrimination or prejudice? A large sample field experiment', Review of Economics and Statistics, 96(1), pp. 119-34.

Heckman, J. (1998). 'Detecting discrimination', Journal of Economic Perspectives, 12(2), pp. 101-16.

Heckman, J. and Siegelman, P. (1993). 'The Urban Institute audit studies: Their methods and findings'. In Clear and Convincing Evidence: Measurement of Discrimination in America, edited by Michael Fix and Raymond J. Struyk, 187-258. Washington, D.C.: The Urban Institute Press.

Jowell, R. and Prescott-Clarke, P. (1970). 'Racial discrimination and white-collar workers in Britain’, Race, 11(4), pp. 397-417.

Lee, H.A. and Khalid, M.A. (2016). 'Discrimination of high degrees: race and graduate hiring in Malaysia', Journal of the Asia Pacific Economy, 21(1), pp. 53-76.

Mincer, J. (1974). Schooling, Experience, and Earnings. New York: Columbia University Press.

Neumark, D. (2016). 'Experimental research on labor market discrimination.' NBER Working Paper No. 21262. Cambridge, MA: NBER.

Neumark, D. (2012). 'Detecting discrimination in audit and correspondence studies', Journal of Human Resources, 47(4), pp. 1128-157.

Neumark, D., Burn, I. and Button, P. (2016). 'Experimental age discrimination evidence and the Heckman critique.’ American Economic Review, 106, pp. 303-308.

Nunley, J., Pugh, A., Romero, N., Seals, R. (2015). 'Racial Discrimination in the Labor Market for Recent College Graduates: Evidence from a Field Experiment', B.E. Journal of Economic Analysis and Policy, 15, pp.1093-1125.

OECD. (2013). International Migration Outlook 2013. Paris: OECD.

Oreopoulos, P. (2011). 'Why do skilled immigrants struggle in the labor market? A field experiment with thirteen thousand resumes', American Economic Journal: Economic Policy, 3(4), pp. 148-71.

Pager, D. (2007). “The use of field experiments for studies of employment discrimination: Contributions, critiques, and directions for the future', The Annals of the American Academy of Political and Social Science, 609(1), pp. 104-33.

Quillian, L., Pager, D., Hexel, O. and Midtboen, A. (n.d.). 'The persistence of racial discrimination: A meta-analysis of field experiments in hiring since 1972', unpublished paper.

Riach, P. and Rich. J. (2002). 'Field experiments of discrimination in the market place', The Economic Journal, 112(483), pp. F480-518.

Rich, J. (2014). 'What do field experiments of discrimination in markets tell us? A meta analysis of studies conducted since 2000’, IZA Discussion Paper No. 8584. Bonn, Germany: IZA.

Zschirnt, E. and Ruedin, D. (2015). 'Ethnic discrimination in hiring decisions: A meta-analysis of correspondence tests 1990-2015’, unpublished paper. 
Table 1: Experimental Studies of Discrimination in Labor and Housing Markets Re-examined

\begin{tabular}{|c|c|c|c|c|c|c|}
\hline $\begin{array}{l}\text { Study } \\
\text { (1) }\end{array}$ & $\begin{array}{l}\text { Country } \\
\text { (2) }\end{array}$ & $\begin{array}{l}\text { Years } \\
\text { (3) }\end{array}$ & $\begin{array}{l}\text { Minority } \\
\text { (4) }\end{array}$ & $\begin{array}{l}\text { Outcome } \\
\text { (5) }\end{array}$ & $\begin{array}{l}\text { Majority } \\
\text { call-back } \\
\text { rate } \\
(6)\end{array}$ & $\begin{array}{l}\text { Estimated } \\
\text { differential for } \\
\text { minority } \\
\text { (7) }\end{array}$ \\
\hline \multicolumn{7}{|c|}{ A. Labor market field experiments } \\
\hline \multirow[t]{2}{*}{ Baert et al. (2015) } & \multirow[t]{2}{*}{ Belgium } & \multirow[t]{2}{*}{$2011-12$} & \multirow[t]{2}{*}{ Turkish } & Call-back & .329 & $\begin{array}{l}-.082 \\
(.034)\end{array}$ \\
\hline & & & & $\begin{array}{l}\text { Immediate } \\
\text { interview }\end{array}$ & .190 & $\begin{array}{l}-.056 \\
(.026)\end{array}$ \\
\hline $\begin{array}{l}\text { Carlsson and } \\
\text { Rooth (2007) }\end{array}$ & Sweden & $2005-6$ & $\begin{array}{l}\text { Middle } \\
\text { Eastern }\end{array}$ & Call-back & .269 & $\begin{array}{l}-.095 \\
(.009)\end{array}$ \\
\hline \multirow[t]{2}{*}{ Drydakis (2014) } & \multirow[t]{2}{*}{ Cyprus } & \multirow[t]{2}{*}{$2010-11$} & Gay & Call-back & .554 & $\begin{array}{l}-.410 \\
(.010)\end{array}$ \\
\hline & & & Lesbian & Call-back & .523 & $\begin{array}{l}-.411 \\
(.011 \\
\end{array}$ \\
\hline $\begin{array}{l}\text { Lee and Khalid } \\
(2016)\end{array}$ & Malaysia & 2011 & $\begin{array}{l}\text { Malay (vs. } \\
\text { Chinese) }\end{array}$ & Call-back & .221 & $\begin{array}{l}-.152 \\
(.018) \\
\end{array}$ \\
\hline \multirow[t]{6}{*}{$\begin{array}{l}\text { Oreopoulos } \\
(2009)\end{array}$} & \multirow[t]{6}{*}{ Canada } & \multirow[t]{6}{*}{2008} & Chinese & Call-back & .142 & $\begin{array}{l}-.053 \\
(.007)\end{array}$ \\
\hline & & & Indian & Call-back & .142 & $\begin{array}{l}-.056 \\
(.007)\end{array}$ \\
\hline & & & $\begin{array}{l}\text { Chinese- } \\
\text { Canadian }\end{array}$ & Call-back & .142 & $\begin{array}{l}-.063 \\
(.008)\end{array}$ \\
\hline & & & Pakistani & Call-back & .142 & $\begin{array}{l}-.073 \\
(.009)\end{array}$ \\
\hline & & & Greek & Call-back & .142 & $\begin{array}{l}-.035 \\
(.017)\end{array}$ \\
\hline & & & British & Call-back & .142 & $\begin{array}{l}-.031 \\
(.011)\end{array}$ \\
\hline $\begin{array}{l}\text { Bertrand and } \\
\text { Mullainathan } \\
\text { (2004) }\end{array}$ & $\begin{array}{l}\text { United } \\
\text { States }\end{array}$ & $2001-2$ & $\begin{array}{l}\text { Black- } \\
\text { sounding } \\
\text { names } \\
\end{array}$ & Call-back & .097 & $\begin{array}{l}-.030 \\
(.006)\end{array}$ \\
\hline \multicolumn{7}{|c|}{ B. Housing market field experiments } \\
\hline \multirow[t]{2}{*}{$\begin{array}{l}\text { Ahmed et al. } \\
(2010)\end{array}$} & \multirow[t]{2}{*}{ Sweden } & \multirow[t]{2}{*}{2008} & \multirow[t]{2}{*}{ Arab/Muslim } & $\begin{array}{l}\text { Positive } \\
\text { response }\end{array}$ & .514 & $\begin{array}{l}-.171 \\
(.033)\end{array}$ \\
\hline & & & & $\begin{array}{l}\text { Immediate } \\
\text { showing }\end{array}$ & .254 & $\begin{array}{l}-.091 \\
(.024)\end{array}$ \\
\hline \multirow[t]{2}{*}{$\begin{array}{l}\text { Bosch et al. } \\
\text { (2010) }\end{array}$} & \multirow[t]{2}{*}{ Spain } & \multirow[t]{2}{*}{2009} & \multirow[t]{2}{*}{$\begin{array}{l}\text { Moroccan } \\
\text { immigrants }\end{array}$} & $\begin{array}{l}\text { Positive } \\
\text { response }\end{array}$ & .590 & $\begin{array}{l}.133 \\
(.014)\end{array}$ \\
\hline & & & & $\begin{array}{l}\text { Immediate } \\
\text { showing }\end{array}$ & .541 & $\begin{array}{l}-.135 \\
(.014)\end{array}$ \\
\hline \multirow[t]{2}{*}{$\begin{array}{l}\text { Carlsson and } \\
\text { Eriksson (2014) }\end{array}$} & \multirow[t]{2}{*}{ Sweden } & \multirow[t]{2}{*}{$2010-11$} & \multirow[t]{2}{*}{ Arab } & $\begin{array}{l}\text { Positive } \\
\text { response }\end{array}$ & .387 & $\begin{array}{l}-.130 \\
(.012)\end{array}$ \\
\hline & & & & $\begin{array}{l}\text { Immediate } \\
\text { showing }\end{array}$ & .271 & $\begin{array}{l}-.110 \\
(.011)\end{array}$ \\
\hline $\begin{array}{l}\text { Ewens et al. } \\
(2014)\end{array}$ & $\begin{array}{l}\text { United } \\
\text { States }\end{array}$ & 2009 & Black & $\begin{array}{l}\text { Positive } \\
\text { response }\end{array}$ & .503 & $\begin{array}{l}-.090 \\
(.019)\end{array}$ \\
\hline
\end{tabular}

Note: All studies are correspondence studies. Column (7) reports marginal effect from probit models, our estimates, from following tables. In the Oreopoulos study, "Chinese-Canadian” means there was an English first name. 
Table 2A: Estimates for Labor Market Discrimination Studies: Full Specifications

\begin{tabular}{|c|c|c|c|c|c|c|}
\hline $\begin{array}{l}\text { Study } \\
\text { Outcome } \\
\text { Minority group }\end{array}$ & $\begin{array}{r}\text { Ba } \\
\text { Call-back } \\
\text { T } \\
\text { (1) } \\
\end{array}$ & $\begin{array}{l}\text { 15), } \\
\text { ed. interview } \\
\text { es } \\
\text { (2) }\end{array}$ & $\begin{array}{l}\text { Carlsson and Rooth (2007), } \\
\text { Sweden } \\
\text { Call-back } \\
\text { Middle Eastern, males } \\
\text { (3) }\end{array}$ & \multicolumn{2}{|c|}{$\begin{array}{l}\text { Drydakis (2014), } \\
\text { Cyprus } \\
\text { Call-back }\end{array}$} & $\begin{array}{c}\text { Lee and Khalid (2016) } \\
\text { Malaysia } \\
\text { Call-back } \\
\text { Malay } \\
\text { (6) } \\
\end{array}$ \\
\hline \multicolumn{7}{|l|}{ A. Estimates from basic probit } \\
\hline Minority, marginal effect & $\begin{array}{l}-.082 \\
(.034)\end{array}$ & $\begin{array}{l}-.056 \\
(.026)\end{array}$ & $\begin{array}{l}-.095 \\
(.009)\end{array}$ & $\begin{array}{l}-.410 \\
(.010)\end{array}$ & $\begin{array}{l}-.411 \\
(.011)\end{array}$ & $\begin{array}{l}-.152 \\
(.018)\end{array}$ \\
\hline \multicolumn{7}{|l|}{ B. Heteroscedastic probit model } \\
\hline Minority, marginal effect & $\begin{array}{l}-.096 \\
(.034)\end{array}$ & $\begin{array}{l}-.072 \\
(.028)\end{array}$ & $\begin{array}{l}-.095 \\
(.009)\end{array}$ & $\begin{array}{l}-.384 \\
(.040)\end{array}$ & $\begin{array}{l}-.304 \\
(.091)\end{array}$ & $\begin{array}{l}-.201 \\
(.038)\end{array}$ \\
\hline $\begin{array}{l}\text { Marginal effect through level } \\
\text { (unbiased) }\end{array}$ & $\begin{array}{l}.044 \\
(.068)\end{array}$ & $\begin{array}{l}.073 \\
(.087)\end{array}$ & $\begin{array}{l}-.102 \\
(.023)\end{array}$ & $\begin{array}{l}-.476 \\
(.029)\end{array}$ & $\begin{array}{l}-.499 \\
(.016)\end{array}$ & $\begin{array}{l}.244 \\
(.108)\end{array}$ \\
\hline Marginal effect through variance & $\begin{array}{l}-.141 \\
(.065)\end{array}$ & $\begin{array}{l}-.145 \\
(.093)\end{array}$ & $\begin{array}{l}.007 \\
(.026)\end{array}$ & $\begin{array}{l}.093 \\
(.065)\end{array}$ & $\begin{array}{l}.195 \\
(.104)\end{array}$ & $\begin{array}{l}-.445 \\
(.142)\end{array}$ \\
\hline $\begin{array}{l}\text { Standard deviation of } \\
\text { unobservables, minority/non- } \\
\text { minority }\end{array}$ & .49 & .55 & 1.03 & 1.59 & 2.27 & .11 \\
\hline $\begin{array}{l}\text { Wald test, overidentification, ratios of } \\
\text { coefficients equal (p-value) }\end{array}$ & .97 & .93 & .87 & .09 & .64 & .94 \\
\hline $\begin{array}{l}\text { LR test: standard vs. heteroscedastic } \\
\text { probit (p-value) }\end{array}$ & .01 & .10 & .80 & .06 & .01 & .01 \\
\hline $\begin{array}{l}\text { Wald test, ratio of standard deviations } \\
\quad=1 \text { (p-value) }\end{array}$ & .00 & .03 & .79 & .18 & .16 & .00 \\
\hline Controls (job or applicants) & $\begin{array}{r}\text { High edu } \\
\text { distanc } \\
\text { vacancies/un } \\
\% \text { foreign, } \\
\text { jobs, avera } \\
\text { quality, inte }\end{array}$ & $\begin{array}{l}\text {-educated, } \\
\text { luration, } \\
\text { nemployment, } \\
\text { ity, multiple } \\
\text { on wage, job } \\
\text { rate customer }\end{array}$ & $\begin{array}{l}\text { Unemployment spells, cultural } \\
\text { activities, sport, personality, } \\
\text { summer experiences, U.S. high } \\
\text { school, high education, multiple } \\
\text { employers, occupation }\end{array}$ & $\begin{array}{r}\text { Enhan } \\
\text { letters, } \\
\text { reference } \\
\text { applica } \\
\text { type, ref } \\
\text { tester, c }\end{array}$ & $\begin{array}{l}\text { cover } \\
\text { anced } \\
\text { ers, first } \\
\text { esume } \\
\text { ce type, } \\
\text { pation }\end{array}$ & $\begin{array}{l}\text { Occupation, cover letter with } \\
\text { good English, extracurricular } \\
\text { skills, BA from private } \\
\text { university, grades, language } \\
\text { and writing skills stated } \\
\text { (Malay, Chinese), MS Office, } \\
\text { software/accounting skills, } \\
\text { high quality CV, degree or } \\
\text { degree project on CV, pre- } \\
\text { university institution, job ad } \\
\text { stated race }\end{array}$ \\
\hline $\begin{array}{l}\text { Clustered (within-pair design) } \\
\mathrm{N}\end{array}$ & 736 & 736 & $\begin{array}{c}\text { Yes } \\
5,636\end{array}$ & 4,846 & 4,194 & 3,009 \\
\hline
\end{tabular}

Note: In Panel A, the marginal effect is based on the standard formula for a discrete variable, with other variables set at sample means. In Panel B, the continuous approximation for marginal effects is used, with the decomposition in equation (8) immediately below. The standard errors for the two components of the marginal effects are computed using the delta method. The only individual controls for which interactions are not introduced are for other demographic groups. 
Table 2B: Estimates for Labor Market Discrimination Studies: Full Specifications

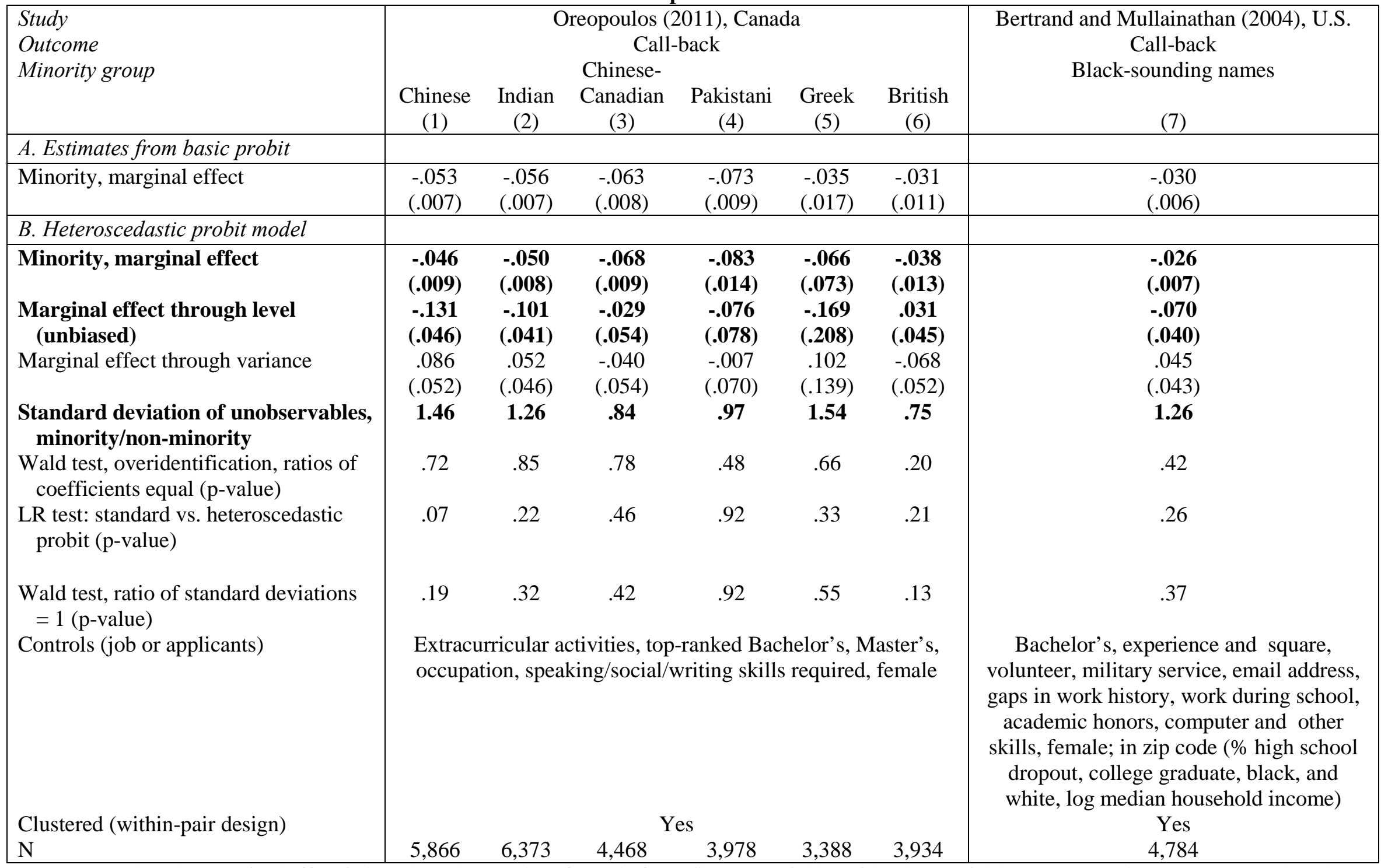

Note: In Panel A, the marginal effect is based on the standard formula for a discrete variable, with other variables set at sample means. In Panel B, the continuous approximation for marginal effects is used, with the decomposition in equation (8) immediately below. The standard errors for the two components of the marginal effects are computed using the delta method. The only individual controls for which interactions are not introduced are for other demographic groups. Some skills are specific to immigrant groups and used to distinguish among immigrants (such as specific language fluencies or where experience obtained), and are not included. 
Table 3: Estimates for Housing Discrimination Studies

\begin{tabular}{|c|c|c|c|c|c|c|c|}
\hline \multirow{3}{*}{$\begin{array}{l}\text { Study } \\
\text { Outcome } \\
\text { Minority group }\end{array}$} & \multicolumn{2}{|c|}{$\begin{array}{l}\text { Ahmed et al. (2010), } \\
\text { Sweden }\end{array}$} & \multicolumn{2}{|c|}{ Bosch et al. (2010), Spain } & \multicolumn{2}{|c|}{$\begin{array}{l}\text { Carlsson and Eriksson } \\
\text { (2007), Sweden }\end{array}$} & \multirow{3}{*}{$\begin{array}{l}\text { Ewens et al. (2014), U.S. } \\
\text { Positive response } \\
\text { Black } \\
\text { (7) }\end{array}$} \\
\hline & $\begin{array}{l}\text { Positive } \\
\text { response }\end{array}$ & $\begin{array}{l}\text { mmediate } \\
\text { showing }\end{array}$ & $\begin{array}{l}\text { Positive } \\
\text { response }\end{array}$ & $\begin{array}{l}\text { mmediate } \\
\text { showing }\end{array}$ & $\begin{array}{l}\text { Positive } \\
\text { response }\end{array}$ & $\begin{array}{l}\text { nmediate } \\
\text { showing }\end{array}$ & \\
\hline & \multicolumn{2}{|c|}{$\begin{array}{l}\text { Arab/Muslim } \\
\text { (1) }\end{array}$} & \multicolumn{2}{|c|}{$\begin{array}{l}\text { Moroccan immigrants } \\
\text { (3) }\end{array}$} & \multicolumn{2}{|c|}{ Arabic/Muslim } & \\
\hline \multicolumn{8}{|l|}{ A. Estimates from basic probit } \\
\hline Minority, marginal effect & $\begin{array}{l}-.171 \\
(.033) \\
\end{array}$ & $\begin{array}{l}-.091 \\
(.024) \\
\end{array}$ & $\begin{array}{l}-.133 \\
(.014) \\
\end{array}$ & $\begin{array}{l}-.135 \\
(.014) \\
\end{array}$ & $\begin{array}{l}-.130 \\
(.012) \\
\end{array}$ & $\begin{array}{l}-.110 \\
(.011) \\
\end{array}$ & $\begin{array}{l}-.090 \\
(.019) \\
\end{array}$ \\
\hline \multicolumn{8}{|l|}{ B. Heteroscedastic probit model } \\
\hline Minority, marginal effect & $\begin{array}{l}-.165 \\
(.034)\end{array}$ & $\begin{array}{l}-.074 \\
(.027)\end{array}$ & $\begin{array}{l}-.136 \\
(.017)\end{array}$ & $\begin{array}{l}-.136 \\
(.017)\end{array}$ & $\begin{array}{l}-.131 \\
(.013)\end{array}$ & $\begin{array}{l}-.113 \\
(.011)\end{array}$ & $\begin{array}{l}-.089 \\
(.019)\end{array}$ \\
\hline $\begin{array}{l}\text { Marginal effect through level } \\
\text { (unbiased) }\end{array}$ & $\begin{array}{l}-.182 \\
(.035)\end{array}$ & $\begin{array}{l}-.146 \\
(.049)\end{array}$ & $\begin{array}{l}-.136 \\
(.018)\end{array}$ & $\begin{array}{l}-.135 \\
(.015)\end{array}$ & $\begin{array}{l}-.134 \\
(.026)\end{array}$ & $\begin{array}{r}-.074 \\
(.034)\end{array}$ & $\begin{array}{l}-.092 \\
(.019)\end{array}$ \\
\hline Marginal effect through variance & $\begin{array}{l}.017 \\
(.019)\end{array}$ & $\begin{array}{l}.072 \\
(.058)\end{array}$ & $\begin{array}{l}.001 \\
(.004)\end{array}$ & $\begin{array}{l}-.001 \\
(.014)\end{array}$ & $\begin{array}{l}.004 \\
(.025)\end{array}$ & $\begin{array}{l}-.039 \\
(.035)\end{array}$ & $\begin{array}{l}.003 \\
(.003)\end{array}$ \\
\hline $\begin{array}{l}\text { Standard deviation of } \\
\text { unobservables, minority/non- } \\
\text { minority }\end{array}$ & 1.20 & 1.35 & .91 & .98 & 1.02 & .85 & 1.08 \\
\hline $\begin{array}{l}\text { Wald test, overidentification, ratios } \\
\text { of coefficients equal (p-value) }\end{array}$ & .59 & .91 & .33 & .52 & .87 & .93 & .07 \\
\hline $\begin{array}{l}\text { LR test: standard vs. } \\
\text { heteroscedastic probit (p-value) }\end{array}$ & .32 & .20 & .74 & .95 & .88 & .26 & .18 \\
\hline $\begin{array}{l}\text { Wald test, ratio of standard } \\
\text { deviations }=1 \text { (p-value) }\end{array}$ & .37 & .29 & .74 & .95 & .89 & .22 & .20 \\
\hline Controls (area or applicants) & \multicolumn{2}{|c|}{$\begin{array}{l}\text { Enhanced application, rent, } \\
\text { space, rooms, metro, } \\
\text { company }\end{array}$} & \multicolumn{2}{|c|}{$\begin{array}{l}\text { Enhanced application, rent, } \\
\text { rooms, urban, company, } \\
\text { female }\end{array}$} & \multicolumn{2}{|c|}{$\begin{array}{l}\text { Jobs, exercise, nightclub, } \\
\text { smoker, references, female, } \\
\text { age }\end{array}$} & \multirow{3}{*}{$\begin{array}{c}\text { Mother's estimated } \\
\text { education, positive email, } \\
\text { negative email, rent, } \\
\text { relative rent, rent in area, } \\
\text { one BR, cost, \% male, \% } \\
\text { black in area/city, female, } \\
\text { Muslim name } \\
\text { No } \\
13.800\end{array}$} \\
\hline Clustered (within-pair design) & & & & & & & \\
\hline & 959 & 959 & 4,716 & 4,716 & 5,827 & 5,827 & \\
\hline
\end{tabular}

Note: In Panel A, the marginal effect is based on the standard formula for a discrete variable, with other variables set at sample means. In Panel B, the continuous approximation for marginal effects is used, with the decomposition in equation (8) immediately below. The standard errors for the two components of the marginal effects are computed using the delta method. The only individual controls for which interactions are not introduced are for other demographic groups. 